\title{
Internet Addiction and Psychological Well-being among Youths of Rajkot District
}

\author{
Mohit M. Pandya ${ }_{1}$, Nitin R. Korat 2
}

\section{ABSTRACT:}

The purpose of present study was to find out correlation between the youths' Internet Addiction and Psychological well-being. The said sample was 120 both males and females in equal numbers was selected through random sampling. Internet Addiction Inventory \&Psychological well-being Inventory are tailor-made instruments, having sufficient reliability and validity. For the purpose of analysis, The Karl-Pearson ' $r$ ' technique was used. Present study reveals the result that there is no significant Negative correlation between the youths' Internet Addiction and Psychological well-being. The authors suggest that there is a need to explore the rural and the urban youths' correlation in the line of above study.

Keywords: Internet Addiction and Psychological well-being

\section{INTRODUCTION:}

Concept of internet addiction was first coined by Goldberg (1996) and by following DSM IV addiction criteria it was defined as "very strong desire or urge for using the internet" (Aboujaoude et al., 2006; Block, 2008; Korkeila et al.2009).Internet is a technological tool which makes our life easier and has become an indispensable part of it while its number of user population increases faster each day (Isman and Dabaj, 2004; Yapici, and Akbayin, 2012). Although internet plays an indirect role on these issues, internet addiction affects these issues directly (Akın, 2012; Young, 1998).

Young (2006) stated that internet is one of the things that influence our daily life because internet users more likely to spend their leisure time in the cyber community. Mythily, Qiu and Winslow (2008), Singapore is a multicultural city-state with a total resident population of just over 3.5 million people, the literacy rate of Singaporeans is $95.4 \%$. Result show that $84 \%$ of the resident with age 10 to 14 years age have started to use the internet, while the internet use for the age of 15 to 59 is $64 \%$. Besides that, $21 \%$ of Singaporean with 60 years and older age group has used the internet. Furthermore, $78 \%$ of household in Singapore have at least one computer no matter is desktop or laptop at home and the $71 \%$ of household have access to the internet at home. The most important thing is $61 \%$ of the individuals are using the internet for leisure activities including playing/downloading games, listening to music or watching films.

${ }^{1} \mathrm{Ph} . D$. Research Scholar, Department of Psychology, Saurashtra University Rajkot- Gujarat-India

${ }^{2}$ Ph.D. Research Scholar, Department of Psychology, Saurashtra University Rajkot- Gujarat-India 
Feel the necessity for using the internet in an increased proportion in order to get the satisfaction they desire (Lee and Shin, 2004); fail in their attempts to control, reduce or give up their internet usage (Widyanto and Griffiths, 2007). Furthermore social sharing sites like Facebook, Twitter, online games and online gambling causes an increase in the number of internet addiction cases and it is stated that internet addiction will become a serious problem in the near future (Andreassen et al., 2012; Herrera et al., 2010; Teke, 2011).

"Well-being is a positive and sustainable condition that allows individuals, groups or nations to thrive and flourish" (Huppert, Baylis \& Keverne., 2005). "A state of complete physical mental and social well-being and does not consist only of the obsess of disease of infirmity" World health organization (WHO-1948). The fundamental proposition of Ryff's psychological well-being model was that subjective well-being (Diener, Lucas, \& Oishi, 2002) wasn't necessarily a condition for mental health (Robbins \& Kliewer, 2000). For example, a psychotic person might say being happy though psychologically distresses. Therefore, additional features are essential in evaluating psychological health (Robbins \& Kliewer, 2000). The analysis of the factors associated with psychological well-being provides a means to understand precisely what it is. As Diener and Suh (2001) suggest, emotions are good predictors of psychological wellbeing. The purpose in this study was to examine the subjective perception that undergraduates have of psychological well-being on the basis of proposals from Ryff and Keyes (1995).

Psychological state of amputees is usually shattered, leading to a state of psychological un-wellness. Psychological well-being is a state of complete wellness in the mental status. Below the knee amputees experience a lot of negative feelings and expectations which are sometimes overt or covert. People with below the knee amputation experience anxiety and depression following amputation of the lower extremity, sometimes they experiences low self-esteem, loss of interest in life and can become suicidal. These psychological reactions correlate significantly with age and marital status, and there is no correlation with level of amputation, mode of ambulation and indication for amputation (Mosaku et al, 2009).

\section{OBJECTIVES:}

To check correlation between Internet Addiction and Psychological well-being of Rajkot District youths.

\section{HYPOTHESIS:}

There is no correlation between Internet Addiction and Psychological well-being of Rajkot district youths.

\section{SAMPLE:}

The respondents of the present study 120 young people randomly selected from various Areas in Rajkot district. In present research the total sample consisted of 60 male and 60 female Rajkot district were chosen. 


\section{TOOLS:}

\section{Internet Addiction Test (IAT)}

The IAT was develop by Dr. Kimberly Young, 1998 and it consist of 20 questions was adopted to evaluate the respondents' level of internet addiction. Each item is scored using a fivepoint liker scale, a graded response can be selected $(1=$ "rare" to $5=$ "always"). It covers the degree to which internet use affect daily routine, social life, productivity, sleeping pattern, and feeling. The minimum score is 20 while the maximum is 100 and the higher the score the greater the level of internet addiction. Three types of Internet-user groups were identified in accordance with the original scheme of Young and the scores ranging from 20 to 49 indicate minimal users while scores from 50 to 79 indicate moderate users and the scores from 80 to 100 indicate excessive users. The instrument has exhibited good psychometric properties in previous researches. The reliability for this questionnaire is 0.899 in Cronbach's Alpha (Sally, 2006).

\section{Psychological Well-Being Test}

It was developed by Bhogle and Prakash (1995), was used to measure Psychological well-being. The questionnaire contains 28 items with true and false response alternative. It covers 13 dimensions of psychological well-being. The maximum possible score is twenty eight and minimum is zero. High score indicates high level of psychological well-being. The test retest reliability coefficient is 0.72 and internal consistency coefficient is 0.84 . The author has reported satisfactory validity of the questionnaire.

\section{PROCEDURE:}

In this research two test were administrated individually as well as on young people, which collecting data for the study before attempting the questionnaire the subjects were requested to read the instruction carefully and follow them in true spirits. While the data collection was completed then ' $r$ ' was used to check correlations. 


\section{RESULTS AND DISCUSSION}

\section{Table-1}

Correlation calculation between Internet Addiction and Psychological well-being of Rajkot district youths.

\begin{tabular}{|c|c|c|c|c|c|}
\hline $\begin{array}{c}\text { Sr. } \\
\text { no. }\end{array}$ & Variables & $\mathbf{N}$ & $\mathbf{d f}$ & $\mathbf{r}$ & $\begin{array}{c}\text { Sig. } \\
\text { Levels }\end{array}$ \\
\hline 1. & $\begin{array}{c}\text { Internet } \\
\text { Addiction }\end{array}$ & 120 & 118 & & \\
\hline $\mathbf{2 .}$ & $\begin{array}{c}\text { Psychological } \\
\text { well-being }\end{array}$ & 120 & 118 & -0.15 & N.S. \\
\hline
\end{tabular}

We have seen the table no.1 the correlation between Internet Addiction and Psychological well-being that ' $r$ ' value = 0.15 , so we can say that there was no significant correlation between the respondents Internet Addiction and Psychological well-being. Here, the Negative $r$ value $=-0.15$, which was no significant at 0.05 levels.Hence, Hypothesis is therefore to be accepted and it concluded that there was no significance correlation between respondents Internet Addiction and their Psychological well-being. It means that as Internet Addiction increases the Psychological well-being is increases.

\section{CONCLUSION}

The study presented in Rajkot district youths' Internet Addiction and Psychological Wellbeing of which are not connected to each other in check. Variable Negative correlation was seen between the two. Thus, Youths' Internet Addiction and Psychological Well-being is no correlated with There is Negative Correlation between each other.

\section{REFERENCES}

1.Eliza Ivanova (2013). Their relationship with Well-Being Journal of Education Culture and Society No. 1 Internet addiction and cyberchondria 57-70

2. Jose M. Augusto Landa, Manuel Pulido Martos (2010) Emotionalintelligenceand personality traitsaspredictorsofpsychological well-being in Spanish undergraduates. Social behavior and personality, 38(6), 783-794@ Society for Personality Research (Inc.) DOI $10.2224 / \mathrm{sbp} .2010 .38 .6 .783$

3. Mehmet ÇARDAK (2013). Psychological well-being and internet addiction among university students.TOJET: The Turkish Online Journal of Educational Technology - July 2013, volume 12 issue 3 
4. Nitin R. Korat, Gandharva R. Joshi (2014). Effects of Personal Variables of Call Centre Employees on their Psychological well-being. The International Journal of Indian Psychology: Volume: 01 | Issue: 04 No. 2 | ISSN 2348-5396

5. Ramazan Hasanzadeh, Atefeh Beydokhti and et.al. (2012).The Prevalence of Internet Addiction among University Students: A General or Specific Problem? J. Basic. Appl. Sci. Res., 2(5)5264-5271, ISSN 2090-4304 Journal of Basic and Applied Scientific Research

6. Ryff, C. D., Keyes, C. L. M. (1995). The structure of psychological well-being revisited. Journal of Personality and Social Psychology, 69(4), 719-727.

7. Young K. S. and Rogers R. C. (1998). The relationship between depression and Internet addiction. Cyber Psychology and Behavior, 1, 25-28.

8. Young, K.S. (1998) Caught in the Net: How to Recognize Internet addiction and A Winning Strategy for Recovery. New York, NY: John Wiley and Sons, Inc.

9. Young, K.Y.S. (2007). Cognitive Behavior Therapy with internet Addicts: Treatment Outcomes and implications, Cyber psychology \& Behavior Volume 10, Number 5, 671-679. 